\title{
Challenges and encouraging educational practices: Observations from field experiences
}

\author{
Belete Mebratu \\ Medaille College, USA \\ bmebratu@medaille.edu
}

\begin{abstract}
This study is an analysis of the reported observations of teacher candidates about the challenges and encouraging practices at schools following their field experiences visits required to meet course work and licensure for teaching. The findings of the study indicate that the participants of the study observed that classroom teachers face the challenges of too much workload, meeting the needs of too many students who need support, lack of resources, classroom management, changes of curriculum and policies, and meeting the needs of diverse students. The candidates, however, are encouraged by their observations of the use and applications of a wide variety of instructional approaches, the prevalence of a culture of a community of learners and cooperations, discipline systems, applications of technology and inspiring teachers' professionalism and commitment to make differences in the lives of their students. Ways of addressing the observed challenges include measures of providing support staff and assistants to the classroom teacher, supplying classrooms with adequate resources, efforts to involve parents and guardians in the education of their children and in the affairs of schools, refocusing teacher education programs on those reported areas of challenges classroom teachers face, and ongoing in-service trainings and professional development programs for teachers.
\end{abstract}

\section{Introduction}

Teacher education programs develop partnerships with P-12 schools to enable teacher candidates acquire real life experiences of working with children in a school setting. Such experiences provide enriching and meaningful learning opportunities for prospective teachers which otherwise are impossible to achieve through campus-based course works. Field experiences provide teacher candidates total emersion in real classroom life experiences in advance of assuming the role of an actual teacher. "Field experiences allow candidates to apply and reflect on their content, professional, and pedagogical knowledge, skills, and professional dispositions in a variety of settings with students and adults" (NCATE, 2008, p. 29). These opportunities create real time understanding of a classroom setting to student teachers.

The importance of field experience to strengthen the readiness of teacher candidates for the role of a classroom teacher is well documented (O'Brtian, Stoner, Appel, \& House, 2007). Gentry (2012), however, argues that research is needed to explore "...how field-based experiences affect teacher candidates" (p.2). One of the best ways to learn more about the effects of field experiences is by studying the reports and reflection of preservice teachers following their field experiences. In a similar argument, Capraro, Capraro \& Helfeldt (2010) note that there is a need to evaluate field observation practices with regard to their impacts and contributions to the education of prospective educators.

Cultural and Pedagogical Inquiry, 2013, 5(2), pp. 39-49

ISSN 1916-3460 @ 2013 University of Alberta

http://ejournals.library.ualberta.ca/index.php/cpi/index 
Studies, therefore, are necessary to find out the reported experiences of teacher candidates about their school-based field observations. Such studies are important as they can provide useful insight about teacher candidates' perspectives of their experiences of schools while they are still on campus pursuing their teacher education program. Reports of teacher candidates about their school observations can inform teacher education programs about areas of focus and emphasis in the reform efforts and changes of programs of teacher preparations.

\section{Research questions}

The present study aims at the investigation of the experiences of teacher candidates about their field observations during their visits to schools as part of the requirements for education classes at a School of Education in Western New York area. Specifically, the study is conducted to answer the following research questions:

1. What are the observations that the teacher candidates report that are challenges to a classroom teacher?

2. What are the observations that the teacher candidates report that are encouraging educational practices at schools?

3. What are the ways to improve what the teacher candidates observe are challenges to a classroom teacher?

\section{Methodology}

The participants of the present study are teacher candidates enrolled in a graduate program of study leading to a Master's of Science Degree in Elementary Education. The teacher candidates, without a background in teaching experiences, are studying in a pre-service teacher education program for a Master's Degree and licensure to fulfil the New York State Department of Education requirement to teach at elementary school level of education. The program requires 100 hours of school observations the teacher candidates need to complete as part of a course in pre-student teaching field experiences.

Open-ended survey questions were used to collect the data for the study from the participating teacher candidates following their field observations at schools. The open-ended questions were phrased in such a way to elicit the participants' responses about their overall observations experiences, what they considered were challenges to the classroom teachers, and what they observed as positive and encouraging educational developments and practices in the classrooms. Qualitative methods were used to interpret and analyze the responses of the participants. The analysis is based on content analysis of the short answer responses of the participants to the open-ended survey questions about their experiences of school observations. The content analysis procedures followed the identifications of categories, themes, labeling and classifications of responses into pedagogical constructs. Accordingly, responses of the informants are grouped under categories based on themes for interpretation and analysis for trends and patterns (Cresswell, 2003; Fraenkel, Wallen, \& Hyun, 2012). For data presentation and analysis, the number of responses and percentages are presented in tables. 


\section{Findings}

This section of the report on teacher candidates' experiences of school observations presents the findings of the study based on the presentation and analysis of data with regard to the research questions of study. The section is organized around the research questions of the study with reference to practices that are considered challenging to a classroom teacher, observations that are encouraging and positive developments about educational practices at schools, and some suggestions on the ways to improve the challenges.

\section{Observations considered challenges to a classroom teacher}

One of the questions posed to the teacher candidates who participated in the present study with regard to their school observations was about the observations they think would be challenges and difficult for a classroom teacher. The responses of the informants include issues of work load, too many needy students, classroom management, lack of resources and support, changes of curriculum and policy, and diversity of learners. Table 4 below presents the areas of challenges and participants' responses about the challenges.

\section{Table 4: Observed challenges to a classroom teacher}

\begin{tabular}{|l|l|l|}
\hline Areas of challenges & No of Responses & Percentage \\
\hline Workload & 13 & 19 \\
\hline Too Many to Support & 15 & 22 \\
\hline Lack of Resources/Support & 6 & 9 \\
\hline Classroom Management & 14 & 20 \\
\hline Change of Curriculum/Policy & 4 & 5 \\
\hline Students Diversity & 17 & 25 \\
\hline \multicolumn{1}{|c|}{ Total } & 69 & 100 \\
\hline
\end{tabular}

Too much workload. The respondents of the study noted in their responses that they think there are challenges to a classroom teacher as the result of too much work compared to the time, resources and supports available. The problems they indicated include that teachers are being spread thin, lack of assistance, difficulty to meet the needs of diverse learners, shortage of time for lesson preparations, and difficulty of providing a one-to-one support to every learner. The following statements are expressions of the candidates' observations of the challenges a classroom teacher faces due to too much work.

- "The teacher is spread too thin — with students at varied levels, it is hard to teach as some students need more support than others"

- "The teacher needs more assistance throughout the day to meet the needs of the students"

- "Differentiated instruction can be challenging at times with so many students and just one teacher"

- "Preparation time"

- "Preparation for each lesson"

- "Preparation for all subject areas"

- "Lack of professional support (EAs, Counselors)" 
- "Time management"

- "Proving one-on-one support to each student individually"

Students who need more support. While there are shortage of time and supports, the respondents of the study noted, there are too many learners who need special and one-on-one support from a classroom teacher. The respondents indicated that there are challenges to a classroom teacher due to factors related to English Language Learners, lots of poverty, handling inclusion classes, students with IEPs, students missing class when they are out for support, and lack of assistants. The followings are statements expressed by the respondents about teachers' challenges as the result of having too many students who need support.

- "Many students who have English as a second language"

- "A lot of poverty"

- "Meeting the individual needs of all students in an inclusive classroom"

- "Students with IEP and other behavior problems"

- "An inclusive classroom was challenging to the teacher because she had to prepare remedial and enrichment activities"

- "Pulling students out for services—-students miss work"

- "Inclusive classrooms"

- "Having an inclusive class"

- "Inclusion"

- "Inclusion classrooms"

- "Number of students on IEP"

- "The number of students with IEP and the lack of additional support"

- "The inclusion classrooms may be difficult for teachers to handle"

- "The challenging factors of inclusion classrooms"

Lack of resources and support. The challenges to a classroom teacher due to having too many students who need special support is further compounded due to the problem of lack of resources and support. The informants of the study indicated that they think some of the challenges classroom teachers face are as the result of the absence of support from some parents and the lack of resources. These concerns are expressed in the respondents' statements listed below.

- "Parents who are not involved"

- "since students did not have much support from parents, their confidence level are low"

- "Attendance issues. Parent participation-some parents are not involved in their children's education"

- "Working with limited use of supplies"

- "Resource provided for teachers is minimal"

- "Not enough resources for the teacher"

- "Lack of resources"

- "Not having enough resources"

Classroom management. Classroom management is reported as one of the areas in which classroom teachers face challenges. The participants of the study expressed concerns that running smooth classes without interruptions and behaviors issues is not easy and the teacher 
needs to work hard to achieve complete discipline. They expressed the areas of challenges to a classroom teacher with regard to classroom managements as in the following statements.

- "Classroom management-specifically, getting their students to follow procedures, listen and behave in an effective, firm, yet friendly way"

- "It is challenging when students are misbehaving, the entire class then falls behind"

- "Management of the classroom was sometimes difficult"

- "Classroom management, handling extremely difficult"

- "Classroom management"

- "Disciple problem unexpected interruptions"

- "Behavior management-I did not realize how complex this issue"

- "Behavior management"

- "Taking control of a classroom when they are out of control"

- "Gaining control in the classroom right at the start of the school year"

- "Classroom management — each class had a few students that would not follow any rules"

- "The behavioral issues that teachers have to address and family matters"

- "Classroom management"

- "Dealing with behavioral issues in the classroom"

Changes of policy. Teacher candidates who are the participants of the present study believe that frequent changes of polices, changes of curriculum and requirements are sources of challenges for classroom teachers. They stated the following statements to express their concerns about changes of curriculum and policies as the source of challenges for teachers.

- "The implementation or change of testing for reading - teachers are learning a new method for students reading level — teachers must learn and adapt to these new rules"

- "Time management-finding the time to teach all of the required materials, and properly administer assessments such as running records"

- "Working with administration---some teachers wanted to expand time on subject areaadministration wants everyone on same page same day"

- "Curriculum expectations"

Students' diversity. Students' diversity is reported as a source of challenges to a class room teacher in the present study of teacher candidates' experiences of school observations. The participating teacher candidates expressed that it is challenging to a classroom teacher to deal with and handle matters related to diversity of learners. They indicated that teachers have to handle the planning, presentation and assessment of lessons to different students of varying learning styles, levels, needs, interest, and conditions. The candidates expressed that teachers have to adapt instructional activities to the diverse situations of the learners which is viewed to be challenging. Diversity of learners is among the factors to receive the highest number of responses $(25 \%$, Table 4$)$ indicating what the teacher candidates consider as the most challenging to classroom teachers. The informants expressed the following statements with reference to their position about the challenging nature of meeting the diverse needs of learners.

- "Diversity of the classroom"

- "Dealing with diversity in the classroom" 
- "Teachers having to deal with diversity in the classroom"

- "Catering to the different learning styles in the classroom and disabilities"

- "So many different learning styles"

- "Engaging all types of students with materials presented"

- "Making lessons exciting to everyone everyday"

- "Keeping all students engaged in learning"

- "Being able to work with diverse groups of learners"

- "Having divers classrooms of diverse learners with different needs, fulfilling curriculum standards"

- "They teach children with so many different learning levels"

- "The difference among students and the different levels they are at"

- "Adapting to learning styles"

- "The various teaching styles teachers use to complete successful learning"

- "Some students are not wanting to participate or become engaged"

- "Some students did not even want to be at school or learn therefore their grades were displaying failing grades"

- "I experienced some students get up in the middle of class and walk out"

The respondents of the study believe that classroom teachers face challenges in their day-to-day routines. The areas of challenges are too much work load, too many students with needs for support from their teachers, lack of resources and support, classroom managements, changes of curriculum and policies, and meeting the needs of diverse of learners.

\section{Encouraging educational practices observed}

Asked about any encouraging educational practices they might have observed during their school visits, the participating teacher candidates of the study identified areas of positive developments. These areas of encouraging educational observations include the use of various instructional strategies and approaches, a culture of a community of learners, discipline system, technology application, and exemplary teachers' behavior. Table 5 below presents the areas of encouraging educational practices observed.

Table 5: Encouraging observations in classrooms

\begin{tabular}{|l|l|l|}
\hline Encouraging areas & No of Responses & Percentage \\
\hline Instructional Approaches & 13 & 17 \\
\hline Community of Learners & 16 & 21 \\
\hline Discipline & 23 & 31 \\
\hline Technology & 5 & 7 \\
\hline Teachers' Behavior & 18 & 24 \\
\hline & 75 & 100 \\
\hline
\end{tabular}

Diverse instructional approaches. The teacher candidates who participated in the study noted that they observed encouraging practices with regard to the use and application of various instructional approaches and strategies in the classrooms they observed. In their responses, the teacher candidates noted that they appreciated the use of various methods of instruction, use of small groups, routines, engaging lessons, field trips, step-by-step teaching, adaptive classes, 
motivation techniques, learning centers, and activities that allow movements. The respondents used the following statements to express their encouraging observations regarding the employments of diverse instructional approaches and strategies.

- "Incorporation of lecture, group work, one-on-one and independent work"

- "Effective reading/small group instruction"

- "Routines - calendar, learning centers-sustained silent reading"

- "The students responded favorably to - "Kid In Charge" program"

- "Creative engaging lessons"

- "Field trips"

- "Step by step teaching"

- "Classrooms are more adaptive and less strict than they once were"

- "Classroom extrinsic motivation"

- "How to use learning centers reading journals"

- "The focus was on morning calendar routine"

- "Activities that encourage movement throughout the classroom"

- "Empowering students/having them get motivated"

Community of learners. The respondents of the present study expressed their appreciations of observing a sense of community of learners and co-operations among students and other schools members as one of the encouraging educational practices during their school visits. They indicated that it is encouraging to observe older students supporting younger ones, literacy buddies, group effort in decorating classrooms, kindness among students, teachers' support, unity among teachers, students' motivation and desire to learn, and diversities of cultures. The respondents stated the following statements expressing their encouragements to observe a culture of a community of learners at the schools they observed.

- "Older students helping younger ones"

- "Literacy buddies-younger kids would par up with older students and read"

- "A group effort in the classrooms decorating can test. The students all worked very hard and they won"

- "Students were kind to each other and used great manners"

- "Students showing support for other classmates - this is encouraged by the teacher"

- "The daily physical exercise routine-where all classes stop and dance for several minutes"

- "Group work"

- "Children look up to their teachers more than anyone"

- "When you are supportive of your students, your students will give you 100\% back"

- "Unity in lessons between teachers"

- "Faculty/staff, teachers, students functioned as a community"

- "School support systems"

- "An extremely fun and exciting field trip to the zoo - the children were so happy and attentive"

- "Encouraging to see all class students to give example based on the lesson"

- "Students really wanted to learn" 
- "The way the children embraced instruction"

- "Seeing students understand a concept"

- "Appreciation of diversities and cultures within the schools"

Discipline system. One of the areas that the teacher candidates believe that it is an encouraging educational practice at schools is what they consider as the prevalence of good discipline. They reported that they observed effective classroom management techniques, character education, teachers' emphases on good behaviors, reward systems, school spirit, and walking in a hall procedure. The teacher candidates are encouraged to see effective behavioral management system and desirable students' behaviors at the schools they visited. The following statements are what the participants stated to express their encouragements about discipline at schools.

- "Effective use of a school wide discipline system"

- "Effective use of a classroom management tool-kit"

- "Excellent character education implementation"

- "Work with the positive before the negative"

- "Teachers recognize good behavior rather than recognizing and acknowledging only bad behavior"

- "Outlining the rules and classroom expectations"

- "Rewarding positive behavior"

- "Teacher knew her students"

- "Tangible awards"

- "Behavior systems/ positive reinforcement"

- "Behavior system for younger children"

- "Character education program"

- "I observed great classroom management"

- "School spirit was encouraged and the kids actively participated"

- "Award ceremony"

- "Bathroom breaks after specials allows students to go bathroom at appropriate time"

- "Behavior management classroom rules/procedures"

- "Walking in the hall procedures"

- "Behavioral techniques for different students"

- "Reward system"

- "Behavior management"

- "Character building"

- "Positive reinforcement"

Technology. Technology is reported to be another area of encouraging educational practice teacher candidates observed in classrooms they observed. They pointed out that the prevalence of new technology such as Smartboard is encouraging.

- "Utilizing Smartboard and interactive activities with students to keep them engaged"

- "Students are more engaged if everyone is involved (technology-Smartboard)"

- "New technology"

- "The use of technology in the classroom" 


\section{- "Technology uses and forms"}

Teachers' behavior. The participating teacher candidates of the present study are encouraged by the professional qualities of teachers they observed in classrooms they visited. The participants reported about teachers' behaviors that they were patient, energetic, encouraging, supportive and confident in their teaching. The participants also noted that teachers care about students, make a difference, go above and beyond, treat each student equally, and make each student feel comfortable. They think the teachers' behaviors they observed are encouraging about what is happening at the schools they observed. The candidates used the following statements to express their observations about teachers' exemplary professional behaviors.

- "In difficult behavior situation the teacher stuck with it; they care about the students and their academic success"

- "Teachers were patient and understanding with students"

- "It encourages that teacher to do well and have confidence teaching"

- "Teachers who care enough to make a difference"

- "Teachers going above and beyond after school program, i.e. extra help"

- "Teachers who really care about success of students"

- "Teachers" patience"

- "There are many dedicated teachers who truly care about their students"

- "Positive feedback from teachers"

- "The teacher treats each student equally"

- "The teacher I observed love the profession, very enthusiastic to see us"

- "Energy of teachers"

- "Making each student feel comfortable"

- "Encouraging children, reading tests to them"

- "Teacher support"

- "How a teacher affect the life of students"

The teacher candidates who participated in the study reported that there are positive and encouraging educational practices at the schools they visited. The candidates are encouraged by the use and applications of a wide variety of instructional approaches, the prevalence of a culture of a community of learners and co-operations, discipline systems, applications of technology and inspiring teachers' professionalism and commitment to make differences in the lives of their students.

\section{Ways of improving and coping with the challenges}

The findings of the present study indicate that the participants of the study observed that classroom teachers face the challenges of too much workload, meeting the needs of too many students who need support, lack of resources, classroom management, changes of curriculum and policies, and meeting the needs of diverse students. These issues are reported as challenges in the eyes of the teacher candidates who observed classrooms as lived by pupils and teachers. When such challenges become part of the realities of classrooms, they can have impacts on the teaching effectiveness of teachers and thus on the quality of education in those classrooms. Some 
measures and approaches are worth considering in improving the reported challenges when they exist.

Providing support staff and assistants to the classroom teacher would alleviate many of the challenges observed. Support and assistant personnel can help the classroom teachers to address the needs of special need students of various conditions. This measure would also relieve teachers some of the workload issues the teacher candidates reported as burdens on classroom teachers. While supplying classrooms with adequate resources facilitates the work of classroom teachers, such measure would also contribute to the improvement of the quality of education. Continuous efforts to involve parents and guardians in the education of their children and in the affairs of schools would provide some of the supports classroom teachers need.

Refocusing teacher education programs on those reported areas of challenges classroom teachers face can be beneficial to enable teacher candidates develop the readiness in managing the challenges. Aspects of the challenges identified in this study in the areas of classroom management, meeting the needs of diverse learners, and changes in curriculum and policies can be brought into the focus of the educational experiences of student teachers as topics for study in their teacher education programs. Strategies of handling classroom management challenges can be highlighted in course works and projects. Various methods and techniques of handling and meeting the needs of diverse needs can be emphasized in teacher education courses that can help prospective teachers develop the skills and mechanisms of managing and coping with the challenges. These measures involve strategic realignments and targeted approaches to the study of the subject matters of those reported challenges that are already parts of the teacher education programs, while in some cases, an introduction of new areas of study is necessary to meet the changing demands of schools.

In addition to the pre-service education of prospective teachers to prepare them in the ways of meeting the demands of becoming classroom teachers, ongoing in-service trainings and professional development programs would be instrumental in enabling classroom teachers manage the challenges they face in the realities of our today's classrooms.

\section{Summary and conclusions}

The purpose of this study has been to investigate teacher candidates' experiences of school observations in terms of challenging teachers' roles and encouraging educational practices. Forty-nine candidates enrolled in a pre-service teacher education graduate program leading to Master's of Science Degree in Education participated in the study. The participants responded to open-ended survey questionnaires that were used for interpretation and analysis following the methods and procedures of content analysis.

The findings of the study reveal that teacher candidates consider some of their observations to be challenging to a classroom teacher. The observed teachers' challenges include high volume of workload, too many needy students for support, lack of parental support and resources, classroom management, frequent changes of curriculum and policies, and students' diversities. Providing support staff and assistants, supplying adequate resources, involving parents and guardians, pre-service preparations, and in-service training and professional development programs would help to manage and improve the challenging situations when they exist. The results of this study, on the other hand, inform that the teacher candidates observed encouraging educational practices at schools. The positive practices identified as encouraging are the 
applications of diverse instructional approaches and strategies, prevalence of a culture of community of learners and co-operations, students' discipline, use of technology, and exemplary teachers' behaviors of professionalism and devotion for learners.

In conclusion, the teacher candidates' experiences of classroom observations during their school visits provide significant amount of exposures and real time lessons about the totality of classroom life in which the teacher and the students strive and thrive to make differences. Field experiences are critically enriching for teacher candidates where they can identify teachers' challenges and appreciate encouraging endeavors and inspiring commitments at schools. Lessons learned from such experiences can inform teacher education programs and policy makers make reforms and changes necessary to improve educational practices.

\section{References}

Capraro, M., Capraro, R., \& Helfeldt, J. (2010). Do different types of field experiences make a difference in teacher candidates' perceived level of competence? Teacher Education Quarterly, 37(2), 131-154.

Creswell, J.W. (2003). Research design: Qualitative, quantitative, and mixed methods approaches (2nd edition). Thousand Oaks, CA: Sage.

Fraenkel, J., Wallen, N., \& Hyun, H. (2012). How to design and evaluate research in education ( $8^{\text {th }}$ edition.). New York: McGraw Hill Companies, Inc.

Gentry, R. (2012). Clinical experience for teacher candidates: Taking preparation beyond the four walls. Research in Higher Education Journal, Vol. 15, 1-13.

NCATE. (2008). Professional standards for the accreditation of teacher preparation intuitions. National Council for the Accreditation of Teacher Education: Washington, DC.

O’Brtian, M., Stoner, J., Appel, K., \& House, J. (2007). The first field experience: Perspectives of pre-service and cooperating teachers. Teacher Education and Special Education, 30(4), 264-275.

Sivakumaran, T., Holland, G., Clark, L., Heying, K., Wishart, W., \& Flowers-Gibson, B. (2011). University-school partnership for clinical experiences: Design, implementation, assessment, and data collection. Journal of Case Studies in Education, Vol. 1, 1-9. 